\title{
PENURUNAN TINGKAT DEPRESI PADA PASIEN DENGAN INTERVENSI MINFULNESS SPIRITUAL ISLAM
}

\author{
Asiah", Meidiana Dwidiyanti, Diyan Yuli Wijayanti \\ Program Studi Magister Keperawatan Konsentrasi Jiwa Universitas Diponegoro Semarang \\ *asiahaby.9@gmail.com
}

\begin{abstract}
ABSTRAK
Gangguan depresi salah satu masalah kejiwaan yang sering ditemukan, menyebabkan gangguan kualitas hidup yang berat hingga dapat membuat penderitanya melakukan percobaan bunuh diri.Intervensi mindfulness spiritual islam merupakan suatu latihan yang melibatkan Allah SWT dalam setiap proses dengan tujuan membantu individu untuk secara sadar memahami kondisi atau pengalaman yang dihadapi bukan sebagai kebetulan tetapi peristiwa dibuat oleh Allah SWT. Tujuan dari penelitian ini untuk menganalisis pengaruh mindfulness spiritual islam terhadap tingkat depresi pada pasien di RSJ. Quasi experimental with control group pre test -post testdesign. Populasi 195, purposive sampling dengan kriteria inklusi dan ekslusi, jumlah sampel 50 responden. Pengukuran tingkat depresi dengan BDI, Kelompok Intervensi menggunakan SOP mindfulness spiritual islam sebanyak 6 kali. Analisa bivariate menggunakan uji statistik Mann Witney U Test. Pada uji MannWhitney Test terdapat perbedaan tingkat depresi sesudah diberikan intervensi $(p=0,000<0,05)$, sehingga ada pengaruh intervensi Mindfulness dalam menurunkan tingkat depresi pada pasien diRSJ.
\end{abstract}

Kata kunci: mindfulness spiritual islam, depresi

\section{REDUCE DEPRESSION LEVEL IN PATIENTS WITH ISLAMIC SPIRITUAL MINFULNESS INTERVENTION}

\begin{abstract}
Depressive disorder is one of the psychiatric problems that is often found, causing severe quality of life disorders that can make sufferers carry out suicide attempts. Islamic spiritual mindfulness interventions are exercises that involve Allah SWT in every process intending to help individuals to consciously understand the conditions or experiences encountered not as coincidences but events created by Allah SWT. The purpose of this study was to analyze the influence of Islamic spiritual mindfulness on the level of depression in patients at the Mental Hospital. Quasi-experimental with control group pre-post test design. Population 195, purposive sampling with inclusion and exclusion criteria, sample of 50 respondents. Measuring the level of depression using the BDI questionnaire, the Intervention Group used the Standard Operating Procedure of Islamic spiritual mindfulness 6 times. Research at Dr. Amino Gondohutomo Mental Hospital, Central Java Province in 2019. The results of the study were analyzed using the Mann-Whitney test, there were differences in the degree of depression after being given an intervention $(p=0,000<0.05)$, there was an influence of the Mindfulness intervention in reducing the level of depression in patients at the Mental Hospital.
\end{abstract}

Keywords: islamic spiritual mindfulness, depression

\section{PENDAHULUAN}

World Health Organization (WHO), menjabarkan pervalensi kasus depresi bahwa sekitar 800.000 orang per tahun meninggal karena depresi berat, dengan angka kematian tertinggi pada usia 15-29 tahun, dan depresi terjadi pada $5.1 \%$ dari seluruh populasi wanita dan $3.6 \%$ dari populasi pria. Depresi juga dialami oleh semua kelompok usia (WHO, 2017).World Health Organization (WHO), menyatakan bahwa gangguan depresi berada pada urutan keempat penyakit di dunia.
Sedangkan di Indonesia prevalensi penderita depresi adalah 3,7 \% dari populasi. Sehingga sekitar 9 juta orang yang mengalami depresi, dari 250 juta jiwa penduduk.(WHO, 2017).

Data hasil Riskesdas 2018, pervalensi depresi pada penduduk umur $\geq 15$ tahun terdapat $91 \%$ penduduk indonesia tidak minum obat (Kemenkes R.I, 2018). Ada sekitar 1.99\% atau 33.186 penduduk kota semarang termasuk kedalam orang dengan gangguan jiwa (OGDJ) dari 1.667.131 jiwa total seluruh penduduk 
kota semarang. Jenis gangguan jiwa terbanyak adalah gangguan psikotik/skizofrenia 750 jiwa, gangguan psikotik akut 276 jiwa, gangguan depresi 96 jiwa dan gangguan bipolar sebanyak 23 jiwa (Dinkes Semarang, 2018). Data RSJD Dr. Amino Gondohutomo Provinsi Jawa Tengah Semarang pada periode 2018 menjabarkan bahwa jumlah pasien rawat inap sebanyak 7.040 orang. Data untuk pasien depresi rawat inap sebanyak 195 orang (Rekam Medik RSJD Dr. Amino Gondohutomo, 2018).

Depresi adalah penyakit lazim di seluruh dunia, di negara maju maupun berkembang. Definisi dari depresi adalah gangguan mental yang ditandai dengan adanya perasaan sedih, kehilangan minat atau kesenangan, penurunan energi, perasaan bersalah atau rendah diri, gangguan tidur atau nafsu makan, kurangnya konsentrasi, dan adanya gejala kecemasan (WHO, 2012). Gangguan depresi merupakan salah satu masalah kejiwaan yang paling sering ditemui. Depresi dapat menyebabkan gangguan kualitas hidup yang berat hingga dapat membuat penderitanya melakukan percobaan bunuh diri (Hawari, 2016).

Dimensi spiritual berupaya untuk mempertahankan keharmonisan atau keselarasan dengan dunia luar, berjuang untuk menjawab atau mendapatkan kekuatan ketika sedang menghadapai stress emosional, penyakit fisik, atau kematian. Kekuatan yang timbul diluar kekuatan manusia ( Hamid, 2008 ; Fitria. A, 2015). Spiritualitas merupakan bentuk keyakinan dalam hubungannya dengan Tuhan Yang Maha Esa dan Maha Pencipta serta sebagai kekuatan hidup yang berguna bagi masyarakat dan lingkungan majemuk tanpa harus kehilangan identitas diri. Keyakinan spiritual akan berupaya mempertahankan keharmonisan, keselarasan dengan dunia luar Dwidiyanti. M, 2008).Keyakinan spiritual merupakan dimensi yang sangat penting dalam keperawatan karena dapat mempengaruhi tingkat kesehatan dan perilaku dalam keperawatan diri pasien. Kesadaran dalam konsep ini akan melahirkan keyakinan dalam keperawatan bahwa pemberian asuhan keperawatan hendaknya bersifat holistik, tidak hanya memenuhi kebutuhan secara fisik, tetapi juga memenuhi kebutuhan psikolohis, social dan spiritual pasien. Spiritual islam memberikan gambaran terpenuhinya kebutuhan spiritual apabila seseorang mampu mengembangkan rasa syukur, sabar dan ikhlas. Spiritual bukan agama tetapi dapat merupakan salah satu jalan mencapai spiritualitas (Yusuf. A, 2006).

Mindfulness merupakan salah satu penatalaksanaan non farmakologi yang dapat menggunakan depresi (Muhit.A, 2015).Mindfulness sebagai latihan menyadari kondisi yang dialami tubuh, pikiran, perasaan, pada situasi saat ini, dan berfikir secara sadar untuk membuat perasaan atau situasi yang tenang (Dictoinary \& Thesaurus, 2017 ; Kabatt-Zinn. J, 2012).Dapat disimpulkan bahwa mindfulness merupakan latihan seseorang untuk menyadari tentang kondisi sehingga mampu membuat tujuan dan fokus dalam menyelesaikan masalah yang dihadapi melalui perubahan perilaku untuk meningkatkan kepasitas dalam menghadapi masalah. Tujuan intervensi mindfulness memiliki indikasi untuk target sehat mandiri yaitu pada seseorang yang mengalami masalah kesehatan jiwa seperti kecemasan, stress dan depresi (Dwidiyanti. M, 2017).

Perkembangan mindfulness telah berkembang dibeberapa negara. Tradisi keagamaan Hindu dan Budha yang pertama kali menerapkan konsep mindfulness, kemudian berkembang menjadi suatu pendekatan yang termasuk bagian dari intervensi dalam bidang keperawatan holistic yang kemudian dapat diterapkan sesuai keyakinan masyarakat dalam sudut pandang keyakinan spiritual, yang dapat mengatasi berbagai masalah psikologis atau masalah kesehatan jiwa (Mediana. $\mathrm{M}$; Munif.A, 2019).

Penelitian Koening (2012) menjelaskan bahwa Religi/spiritualitas melibatkan keyakinan, praktik dan ritual terkait dengan transenden (Tuhan), atau kebenaran mutlak /realitas dalam tradisi timur (Koening.H.G, 2012). Dan pada pasien depresi mengalami kegagalan/disfungsi spiritual, dimana kondisi ini biasanya sulit untuk dijalani, menghasilkan rasa gagal dan bersalah (Auerbach.R.P, 2010). PenelitianBonelli.R, 2012 mengemukakan bahwa keyakinan atau praktik keagamaan atau spiritual (R/S) dapat digunakan untuk mengatasi atau beradaptasi dengan situasi kehidupan yang penuh tekanan atau depresi (Bonelli.R, 2012).Hasil penelitian pilot study yang menunjukan bahwa 6 responden (54\%) dari 11 responden melakukan kegiatan spiritual 
secara mandiri setelah 7 hari menjalani terapi maindfulness spiritual dengan $p$-value $=0,024$ $(\alpha<0,05)$ yang berarti ada pengaruh intervensi mindfulness spiritual terhadap kemandirian spiritual dan signifikan meningkatkan kepatuhan minum obat pada pasien skizofrenia dengan nilai ( $p-0,23)$ (Dwidiyanti.M, 2018).

Intervensi Mindfulness Spiritual Islam merupakan salah satu intervensi keperawatan dengan menggunakan pendekatan spiritual Islam yang bertujuan untuk mengatasi berbagai masalah psikologis dan gangguan jiwa, seperti kecemasan, stress dan depresi. Fenomena ini menjadi perhatian, dikarenakan saat ini system pelayanan kesehatan jarang mempertimbangkan aspek spiritual disebabkan masih adanya kontroversi tentang penggunaan istilah spiritualitas yang tepat (Dwidiyanti, 2017).Intervensi mindfulness spiritual Islam diharapkan dapat penurunan tingkat depresi pasien . Dari beberapa data yang sudah dijabarkan diatas dapat dijadikan sebagai alasan dasar oleh peneliti untuk melakukan penelitian tentang "pengaruh intervensi mindfulness spiritual islam terhadap tingkat pepresi pada pasien di RSJ". Penelitian ini merupakan jenis penelitian termasuk quasi experimental designwith control group dengan pre test-post test.

\section{METODE}

Jenis penelitian quasi experimental designwith control group. Masing-masing kelompok dilakukan pre test and post test.Penelitian berfokus pada tingkat depresi pada pasien yang dilakukan perawatan di Rumah Sakit Jiwa. Populasi 195 responden, menggunakan purposive sampling dengan kriteria inklusi dan ekslusi, jumlah sampel 50 responden (25 responden kelompok intervensi dan 25 responden kelompok kontrol). Penelitian ini dilakukan diruang rawat inap. Kelompok intervensi diberikan perlakukan dengan menggunakan Standar Operasional Prosedur (SOP)mindfulness spiritual islamdengan dosis sebanyak 6 kali pemberian. Durasi untuk setiap pemberian kepada kelompok intervensi selama 20-30 menit, yang dilakukan oleh perawat (enumerator) ruang rawat inap yang telah memiliki kompetensi mindfulness spiritual islam. Sedangkan untuk pengukuran tingkat depresi menggunakan instrument Back Depression Inventory (BDI) dengan 21 item pertanyaan, pengukuran dilakukan oleh perawat (enumerator). Pengukuran tingkat depresi dilakukan pada kelompok intervensi dan kelompok kontrol pre test dan post test.Tingkatan Depresi berdasarkan penilaian quesioner BDI ada 4 kategori yaitu minimal (nilai 0-13), ringan (nilai 14-19), sedang (nilai 20-29) dan berat (nilai 29-63). Pada penelitiansebelumnya instrumen BDI telah dilakukan uji construc validity pada pasien rawat jalan psychiatric $\alpha=0,92$ dan untuk mahasiswa $\alpha=0,93$. Tekhnik analisa bivariate menggunakan uji statistik Wilcoxon Signed Rank Test (uji kompetensi dua sample berpasangan) dan menggunakan uji statistik Mann Witney U Test.Telah lulus uji etik di RSJD Dr. Amino Gondohutomo Provinsi Jawa Tengah dengan nomor : 420/12972.

\section{HASIL}

Tabel 1 diatas dapat dengan menggunakan Uji Crosstab Chi-square dapat disimpulkan bahwa varian dari variabel usia, jenis kelamin, pendidikan, budaya, status marital, pekerjaan, dan pendapatan signifikan homogen $(p>$ $0,05)$.

Tabel 2 menunjukkan, mayoritas responden pada kelompok intervensi sebelum diberikan intervensi berada pada tingkat depresi berat sebanyak 9 orang $(36,00 \%)$ dan sesudah diberikan intervensi berada pada tingkat depresi minimal sebanyak 18 orang $(72,0 \%)$. Berdasarkan tabel tersebut, mayoritas responden pada kelompok kontrol sebelum diberikan intervensi berada pada tingkat depresi sedang sebanyak 13 orang $(52,0 \%)$ dan sesudah diberikan intervensi berada pada tingkat depresi sedang sebanyak 13 orang $(52,0 \%)$.

Tabel 3 menunjukkan ada perbedaan tingkat depresi pasien di RSJ sebelumdan sesudah dilakukan intervensi pada kelompok intervensi dan kelompok kontroldengan menggunakan paired sample t-test dapat disimpulkan bahwa terdapat perbedaan tingkat depresi pasien pada kelompok intervensi sebelum dan sesudah diberikan intervensi $(\mathrm{p}=0,000<0,05)$, sehingga menggunakan Wicoxon test dapat disimpulkan bahwa terdapat tidak perbedaan tingkat depresi pasien pada kelompok kontrol sebelum dan sesudah diberikan intervensi $(p=$ $0,087<0,05)$. 
Tabel 1.

Karakteristik responden $(n=25)$

\begin{tabular}{|c|c|c|c|c|c|}
\hline \multirow{3}{*}{ Variabel } & \multicolumn{4}{|c|}{ Kelompok } & \multirow{3}{*}{$\begin{array}{c}p \text {-value } \\
\left(X^{2}\right)\end{array}$} \\
\hline & \multicolumn{2}{|c|}{ Intervensi } & \multicolumn{2}{|c|}{ Kontrol } & \\
\hline & f & $\%$ & $\mathrm{f}$ & $\%$ & \\
\hline \multicolumn{5}{|l|}{ Usia } & \multirow{4}{*}{0,723} \\
\hline Remaja & 6 & 24,0 & 5 & 20,0 & \\
\hline Dewasa & 12 & 48,0 & 10 & 40,0 & \\
\hline Lansia & 7 & 28,0 & 10 & 40,0 & \\
\hline \multicolumn{5}{|l|}{ Jenis Kelamin } & \multirow{3}{*}{0,086} \\
\hline Laki-laki & 18 & 72,0 & 11 & 44,0 & \\
\hline Perempuan & 7 & 28,0 & 14 & 56,0 & \\
\hline Pendidikan Terakhir & & & - & - & \multirow{5}{*}{0,451} \\
\hline SD & 13 & 52,0 & 9 & 36,0 & \\
\hline SMP & 5 & 10,0 & 4 & 16,0 & \\
\hline SMA & 5 & 20,0 & 8 & 32,0 & \\
\hline PT & 2 & 8,0 & 4 & 16,0 & \\
\hline \multicolumn{5}{|l|}{ Status Marital } & \multirow{4}{*}{0,579} \\
\hline Kawin & 15 & 60,0 & 14 & 56,0 & \\
\hline Tidak Kawin & 9 & 36,0 & 8 & 32,0 & \\
\hline Duda/ Janda & 1 & 4,0 & 3 & 12,0 & \\
\hline \multicolumn{5}{|l|}{ Pekerjaan } & \multirow{3}{*}{1,000} \\
\hline Bekerja & 12 & 48,0 & 12 & 48,0 & \\
\hline Tidak Bekerja & 13 & 52,0 & 13 & 52,0 & \\
\hline
\end{tabular}

Tabel 2.

Tingkat depresi pasien sebelum dan sesudah dilakukan intervensi pada kelompok intervensi dan kelompok kontrol $(\mathrm{n}=25)$

\begin{tabular}{lcccc}
\hline \multirow{2}{*}{ Variabel } & \multicolumn{2}{c}{ Intervensi } & \multicolumn{2}{c}{ Kontrol } \\
\cline { 2 - 5 } & $\mathrm{f}$ & $\%$ & $\mathrm{f}$ & $\%$ \\
\hline Sebelum Intervensi & & & 0 & 0 \\
\hline Minimal & 0 & 32,0 & 9 & 36,0 \\
\hline Ringan & 8 & 32,0 & 13 & 52,0 \\
\hline Sedang & 8 & 36,0 & 3 & 12,0 \\
\hline Berat & 9 & 100,0 & 25 & 100,0 \\
\hline Total & 25 & & & \\
\hline Sesudah Intervensi & & 72,0 & 0 & 0 \\
\hline Minimal & 18 & 20,0 & 12 & 48,0 \\
\hline Ringan & 5 & 8,0 & 13 & 52,0 \\
\hline Sedang & 2 & & &
\end{tabular}

Tabel 3.

Perbedaan tingkat depresi pasien pada kelompok intervensi dan kontrol sebelum dan sesudah perlakuan $(n=25)$

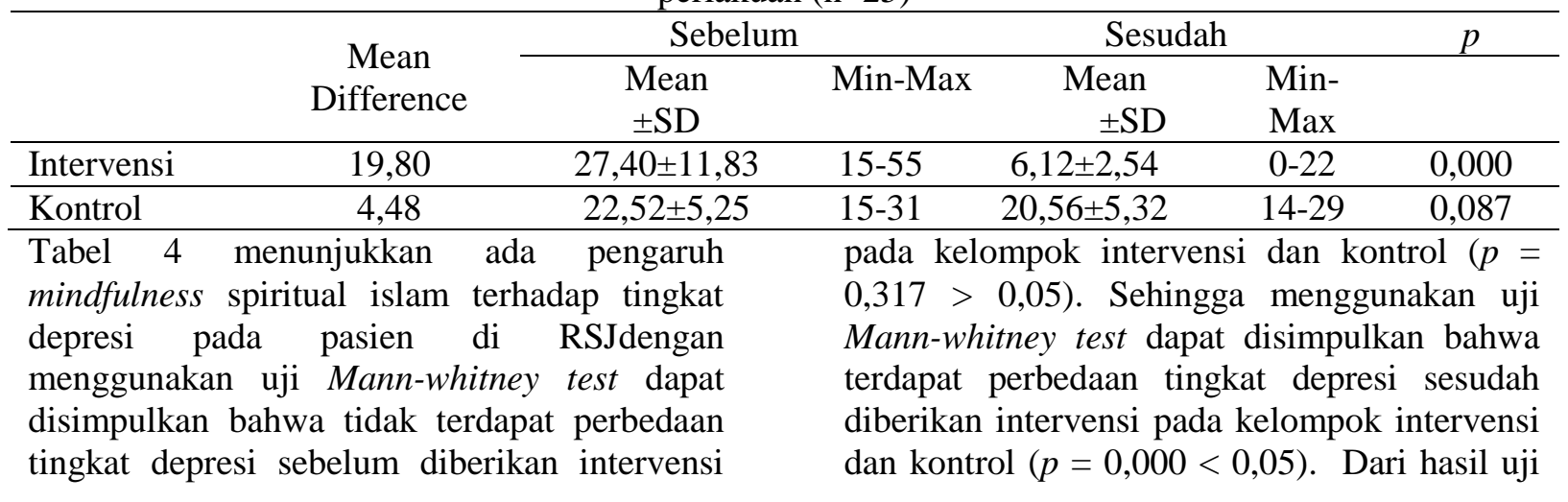


dapat disimpulkan bahwa terdapat pengaruh intervensi mindfulness dalam menurunkan

depresi pasien.

Tabel 4.

Pengaruh intervensi terhadap tingkat depresi pasien $(n=50)$

\begin{tabular}{llrrrrr}
\hline & & \multicolumn{2}{c}{ Intervensi } & \multicolumn{2}{c}{ Kontrol } & \multirow{2}{*}{$P$} \\
\cline { 3 - 7 } & & $\begin{array}{l}\text { Mean } \\
\text { Rank }\end{array}$ & Sum Rank & \multicolumn{1}{c}{$\begin{array}{l}\text { Mean } \\
\text { Rank }\end{array}$} & Sum Rank & \\
\hline $\begin{array}{l}\text { Tingkat } \\
\text { Depresi }\end{array}$ & Sebelum & 27,56 & 689,00 & 23,44 & 586,00 & 0,317 \\
\cline { 2 - 7 } & Sesudah & 14,44 & 224,00 & 45,56 & 912,50 & 0,000 \\
\hline
\end{tabular}

\section{PEMBAHASAN}

Tabel 1 dengan menggunakan Uji Crosstab Chi-square dapat disimpulkan bahwa varian dari variabel usia, jenis kelamin, pendidikan, budaya, status marital, pekerjaan, dan pendapatan signifikan homogen $(p>0,05)$. Hasil tabel 2 didapatkan datatingkat depresi pada pasien sebelum dan sesudah diberikan intervensi memiliki pervalensi berada pada tingkat depresi berat sebanyak 9 orang $(36,00 \%)$ dan sesudah diberikan intervensi berada pada tingkat depresi minimal sebanyak 18 orang $(72,0 \%)$. Dibuktikan pada hasil penelitian pada pasien skizofrenia terdapat peningkatan spiritual pada pasien skizofrenia setelah diberikan intervensi mindfulness spiritual islam yaitu sebelum dilakukan intervensi terdapat $18(78,3 \%)$ spiritual sedang, dan 2 orang $(8,7 \%)$ spiritual rendah. Setelah mendapatkan perlakuan terdapat spiritual tinggi 18 orang $(78,3 \%)$ dan tingkat spiritual rendah sebanyak $0(0 \%)$ (Triyani, 2019).

Hal ini didukung penelitian sebelumnya yang menyebutkan bahwa spiritual merupakan suatu peranan penting dalam kehidupan orang dengan skizofrenia, stress, kecemasan, depresi dan gangguan jiwa lainnya, spiritualitas dapat meningkatkan integritas social, mengurangi resiko bunuh diri dan meningkatkan kualitas hidup. Pemenuhan kebutuhan spiritual dapatmemenuhi kualitas hidup pasien, penelitian quasy experiment kepada 24 responden menunjukan hasil dengan $p$-value $=$ 0,000 terdapat pengaruh pemenuhan kebutuhan spiritual terhadap pasien skizofrenia (Gorver.S, Davuluri.T dan Chakrabarti, 2014 ; Bora.c, Balesteros.J, Schene. A, 2002 ; Aryani.S, 2014).

Alasan penurunan tingkat depresi, bahwa spiritualitas merupakan proses kesadaran menanamkan kebaikan secara alami yang mana menemukan kondisi terbaik bagi kualitas perkembangan yang lebih tinggi.Spiritualitas adalah keyakinan individu dalam hubungannya dengan Yang Maha Kuasa dan Maha Pencipta serta tentang kekuatan hidup yang berguna bagi masyarakat dan lingkungan majemuk tanpa kehilangan identitas diri.Sehingga dengan keyakinan spiritual akan berupaya mempertahankan keharmonisan, keselarasan dengan dunia luar. Berjuang untuk mendapatkan kekuatan ketika sedang menghadapi penyakit fisik, stress emosional, keterasingan sosial, bahkan ketakutan menghadapi ancaman kematian (Hamid.A.Y, 2008 ; Fitria. A, 2015).

Mindfulness spiritual Islam adalah sebagai suatu latihan yang melibatkan Allah SWT sebagai Tuhan yang Maha Kuasa dalam setiap proses (mengingat Allah SWT) dengan tujuan membantu individu untuk secara sadar memahami kondisi atau pengalaman yang dihadapi bukan sebagai kebetulan tetapi peristiwa dibuat oleh Allah SWT (Dwidiyanti; Munif, 2019). Situasi spiritual seseorang, dapat sebagai faktor akibat, tetapi juga dapat menjadi faktor penyebab. Orang-orang yang spiritualnya tinggi memiliki risiko yang rendah untuk terkena depresi, narkoba, usaha bunuh diri dan lebih puas dengan keberadaan dan hidupnya (Suradi, 2015).

Berdasarkantabel 4 didapatkan data $(p=0,000$ $<0,05)$ terdapat perbedaan tingkat depresi sesudah diberikan intervensi pada kelompok intervensi dan kelompok kontrol, sehingga adanya pengaruh yang signifikan bahwa intervensi mindfulnessspiritual islam dalam menurunkan depresi pasien.

Membandingkan intervensi mindfulness spiritual islam dengan Mindfulness-Based Cognitive Therapy (MBCT), bahwa tidak ada perbedaan yang signifikan secara statistik antara kelompok MBCT dan kelompok control. Pada kelompok Mindfulness-Based Cognitive Therapy (MBCT) memiliki pengurangan yang signifikan dalam gejala depresi pada 8 minggu selama berlangsung perlakuan yaitu setelah perawatan $(\mathrm{p}=0,002$; $\mathrm{d}=0,86)$. Selain itu, kelompok MBCT 
mengalami pengurangan kecemasan yang signifikan $(p=0,001 ; d=0,99)$ dan peningkatan kualitas hidup $(p=0,048 ; d=$ 0,35) (Gabriela.S, 2019).

Data Penelitian lain yang mendukung bahwa pilot study yang menunjukan bahwa 6 responden $(54 \%)$ dari 11 responden melakukan kegiatan spiritual secara mandiri setelah 7 hari menjalani terapi maindfulness spiritual dengan $p$-value $=0,024 \quad(\alpha<0,05)$ yang berarti ada pengaruh intervensi mindfulness spiritual terhadap kemandirian spiritual dan signifikan meningkatkan kepatuhan minum obat pada pasien skizofrenia dengan nilai $(p-0,23)$ (Dwidiyanti.M ; Ningsih.H.E.W, 2019).

Target - target sehat mandiri dari Mindfulness Spiritual Islam yang dapat dicapai dengan pemahaman serta pengaplikasian komponenkomponen mindfulness spiritual islam (muqarabah dan taqarub) (Dwidiyanti. M dan Munif.A, 2019). Sedangakan 5 (lima) tahapan intervensi mindfulness spiritual islam dengan tazkiyatun nafs yaitu sebagai berikut : niat dan muraqabah, muhasabah, taubat, rasakan respon qolbiyah dan fisik (body scan), Do'a. Sehingga pasien akan mendapatkan pencapaian peningkatan spiritual, dan perilaku positif yakni dilihat dari tingkat kemandiriannya dalam kegiatan spiritual ibadah berupa berwudhu, sholat, membaca surat-surat pendek Al-qur'an (Al-fatihah, Aliklas, An-nas), berdoa, dan berdzikir (Dwidiyanti \& Munif, 2019).

\section{SIMPULAN}

Terdapat perbedaan tingkat depresi sesudah diberikan intervensi pada kelompok intervensi dan kontrol $(p=0,000<0,05)$. Dari hasil tersebut dapat disimpulkan bahwa terdapat pengaruh intervensi Mindfulness dalam menurunkan depresi pasien.

\section{DAFTAR PUSTAKA}

Aryani. S (2014). Pemenuhan Kebutuhan Spiritualitas Memenuhi Kualitas Hidup Pasien Skizofrenia. 2014 ; Jurnal Kebidanan dan Keperawatan, 10 (1). pp. 64-76. ISSN 1858-0610. UNISA Yogyakarta.

Auerbach.R.P (2010). Understanding the role of coping in the development of depressive symtoms : Symtom specificity, gender differences, and cross-cultural Applicability. British
Journal of Clinical Psychology, vol. 49, no.4, pp. 547-561.doi: 10.1348/014466509X479681.

Bonelli.R (2012). Religious And Spiritual Factors In Depresion : Review and Integration of The Research. Doi:10.1155/2012/962860.

Borra.C, Balesteros.J, and Schene.A (2002). Quality of Life in Patients with Schizophrenia in five European Countries: The EPSILON Study. 2002 ; (15) : 283-92.DOI:10.1034/j.16000447.2002.1169.x.

Cambridge Advaanced Learners Dictoinary \& Thesaurus (2017). Stress. Httpdictionary.cambridge.org/dictionary /English/stress.

Depkes R.I. 2018. Hasil Utama Riskesdas 2018. http://www.kemenkes.go.id.

Dinkes Semarang. 2018. Orang Dengan Gangguan Jiwa di Semarang. https://www.ProfilDinkes-KotaSemarang.

Dwidiyanti.M (2008). Keperawatan Dasar ; Konsep Caring, Komunikasi, Etik dan Aspek Spiritual Dalam Pelayanan Keperawatan. $1^{\text {st }}$ ed. Semarang: Hasani.

Dwidiyanti.M (2017). Mindfulness Caring Pada Stress. UNDIP PRESS : Semarang.

Dwidiyanti. M (2018). The Effect of "Mindfulness Spiritual Islam" on the Meditation Adherence of Patiens with Psychiatric and Mental Health Disorder". J Holist Nurs.

Dwidiyant.M (2019). The Art of Mindfulness Spiritual Islam. Semarang : INDIP Press.

Dwidiyanti. M dan Ningsih.H.E (2019). Concept Analysis of Mindfulness Based on Islam Religion. Jurnal Ilmu Keperawatan (2019) 6:2. ISSN: 23386371, e-ISSN 2550-018X.

Fitria. N (2015). Terapi Psikospiritual Sebuah Hasil Penelitian. https://nitafitria.wordpress.com/2009/0 2/09/terapi-psikospiritual-sebuah-hasil- 
penelitian/. Diakses tanggal 20 Agustus 2017.

Gabriela.S (2019). Mindfulness-Based Cognitive Therapy Intervention for the Treatment of Late-Life Depression and Anxiety Symptoms in Primary Care: A Randomized Controlled Trial.DOI: $10.1159 / 000501214$

Grover.S, Davuluri.T, and Chakrabarti.S. (2014). Religion, Spirituality, and Schizofrenia : A Review. 2014 ; 36 (2).doi: 10.4103/0253-7176.130962.

Hamid. A.Y (2008). Bunga Rampai Asuhan Keperawatan Kesehatan Jiwa. Penerbit EGC. Jakarta.

Hawari (2016). Manajemen Stres Cemas dan Depresi. Jakarta : FKUI.

Kabatt-Zinn.J (2012). Mindfulness and Psychotherapy. Smith College. Studies in Social Work, 84 (1), 132-136. https://doi.org/doi:10.1080/00377317.20 14.861286.

Koening. H.G (2012). Handbook of Religion and Health. Oxford University Press, New York, NY, USA, $2^{\text {nd }}$ edition.ISBN: 9780195335958.

Muhit.A (2015). Pendidikan Keperawatan Jiwa. Teori dan Aplikasi. Yogyakarta : CV. Andi Offset.

Rekam Medik RSJD Amino Gondohutomo (2018). Data Pasien Depresi Rawat Inap. RSJD Dr. Amino Gondohutomo Jawa tengah. Semarang.

Suradi (2015). Kapasitas institusi Wajib Lapor dalam Penanganan Korban Penyalahgunaan NAPZA. Jakarta : P3KS.

Triyani. F.A (2019). Pengaruh Mindfulness Melalui Aplikasi Android Si-SIWATA Terhadap Tingkat SpiritualPasien Skizofreia Di RSJD Dr. Amino gondohutomo Provinsi Jawa Tengah. 2019. Tesis. Universitas Diponegoro Semarang.

WHO (2012). Depression, a global public health concern. WHO Departemen
Mental Health Substance Abuse. 2012; 6-8).

World Health Organization (2017). Depression. Mental Health. Book PDF WHO/MSD/MER/2017.2.https://apps.w ho.int/iris/bitstream/handle/10665/25461 0/WHO-MSD-MER-2017.2-eng.pdf.

World Health Organization (2017). Depression and Other Common Mental Disorders: global health estimates. WHO. 2017:124.

Yusuf. A (2016). Kebutuhan Spiritual : Konsep dan Aplikasi dalam Asuhan Keperawatan. Jakarta : Mitra Wacana Medika. 
Jurnal Keperawatan Jiwa Volume 7 No 3 Hal 267 - 274, November 2019

FIKKes Universitas Muhammadiyah Semarang bekerjasama dengan PPNI Jawa Tengah 